\title{
2005년도 ODA 통계
}

1. $\mathrm{OECD}$ 사무국이 잠정집계한 바에 의하면, 2005년도 DAC 회원국의 ODA는 1,060억불로 서 $\mathrm{DAC}$ 회원국 $\mathrm{GNI}$ 총액의 $0.33 \%$ 이며 2004 년의 795 억불 $(0.26 \%)$ 보다 크게 증가된 바, 이 는 이라크 및 나이지리아에 대한 채무탕감(190 억불)에 기인하며, 채무탕감을 제외할 경우 66 억불(실질가치로 $8.7 \%$ )의 증가를 기록하였음.

※ $\mathrm{ODA}$ 확대 주요요인 및 전망

- 파리클럽 채권단은 이라크 및 나이지리아에 대해 대규모 채무탕감조치에 합의, 2005년 에 이라크 140 억불 및 나이지리아 50 억불의 채무를 탕감하고, 나이지리아에 대해 2006 년 추가 채무탕감, 이라크에 대해 향후 3 년간 추가적 탕감조치가 있을 예정임.

- 2004년 12월 인도양 쓰나미 피해 지원을 위 해 22 억불의 $\mathrm{ODA}$ 제공

- ODA는 2006년 및 2007년에 약간 떨어질 것 으로 예상되나, 최근 ODA 확대공약에 따라 꾸준히 증가추세를 보일 것으로 전망
2. 공여규모면에서 미국, 일본, 영국, 프랑스, 독 일 순이며, 유엔목표치 $0.7 \%$ 를 초과하는 국가 는 예년과 마찬가지로 덴마크, 룩셈부르크, 네 덜란드, 노르웨이, 스웨덴 5 개국에 불과함.

a 미국의 ODA 규모는 270 억불로서 채무탕감액을 제외해도 실질가치로 $16.2 \%$ 가 늘어났으며, $\mathrm{ODA} / \mathrm{GNI}$ 비율은 $0.17 \%$ 에서 $0.22 \%$ 로 증가하 여 1986년 이래 최고치를 기록함. 주요 증가원 인은 이라크 채무탕감(39억불), 이라크 재건지 원(35억불), 아프간 재건 및 마약통제(15억불)임.

- 일본은 130 억불(GNI 비율 $0.28 \%$ )로서 실질가 치로 $12.1 \%$ 증가한 바, 이라크 지원(32억불), 쓰나미 피해 국가에 대한 지원(5.4억불)이 주요 요인임.

- $\mathrm{EU} 15$ 개국은 560 억불(GNI 비율 $0.44 \%)$ 로서 채무탕감 제외시 $3.8 \%$ 실질적으로 증가함. $\mathrm{EU}$ 국가들은 2006년까지 $0.39 \%$ 수준으로 확대하 기로 공약한 바 있으며, 그리스, 이태리, 포르 투갈, 스페인 등이 아직 목표에 미달하고 있고, 
호주와 독일은 부채탕감 때문에 2005년도 목 표를 초과함.

3. non-DAC 공여국 중에는 우리나라를 비롯하 여 체코, 폴란드, 슬로바키아가 2005년도 잠정 통계를 제출하였으며, 모두 상당한 증가세를 기록한 것이 특징임.
- 우리나라는 총 744백만 불(0.09\%)로서 '04년 423백만 불에서 대폭 증가하였으며 이는 주로 양자원조 증가 및 국제기구 출자금 증가에 기 인함.

- 체코는 131 백만 불(0.11\%), 폴란드는 283 백만 불(0.09\%)을 기록하고, 슬로바키아는 56 백만 불(0.12\%)로 전년에 비해 거의 배증 기록

\section{TABLE 1 : NET OFFICIAL DEVELOPMENT ASSISTANCE IN 2005}

Preliminary data

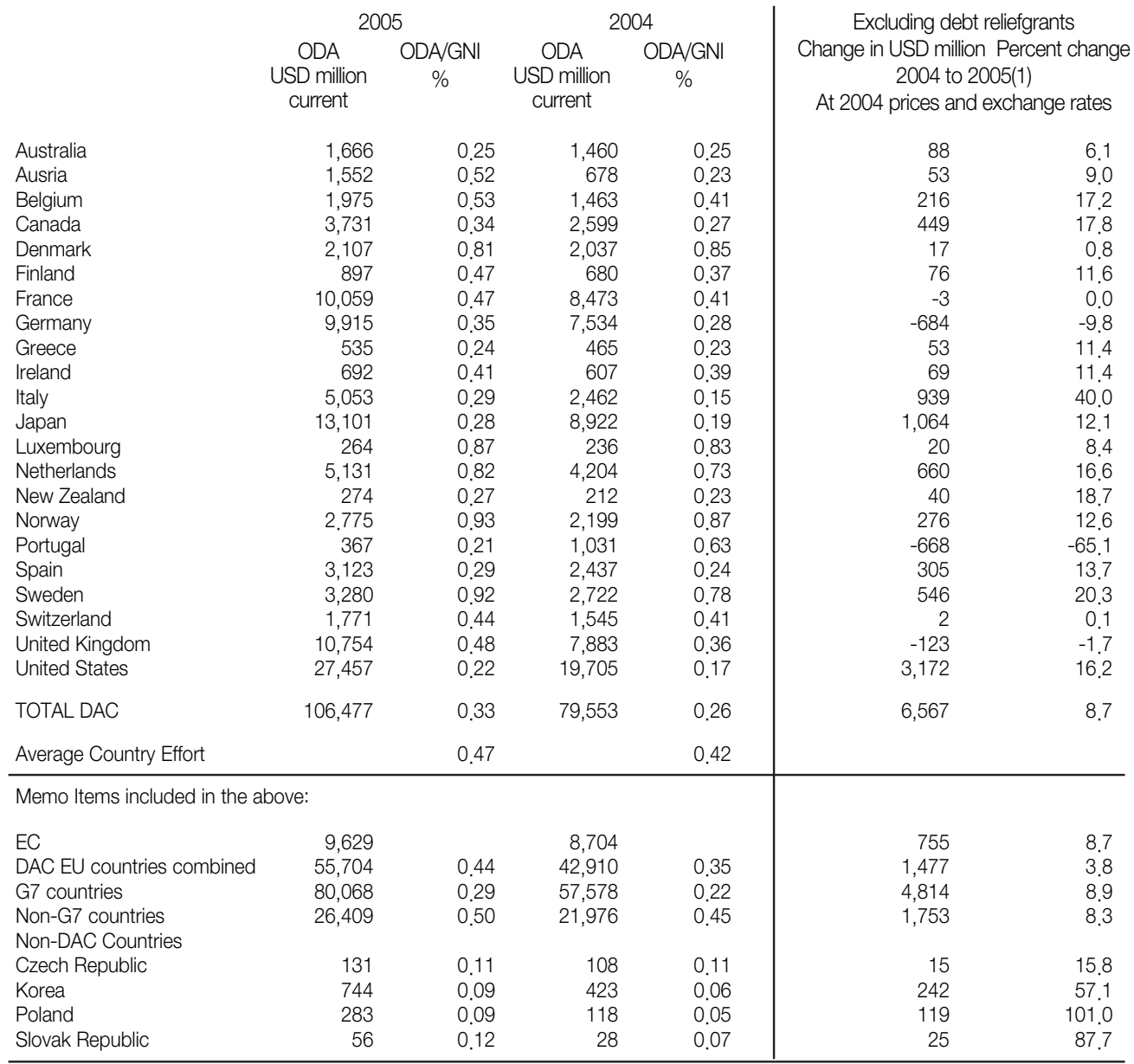

(1) Taking account of both inflation and exchange rate movements

Note: The data for 2005 are preliminary pending detailed final data to be published in December 2006. The data are standardised on a calendar year basis for all donors, and so may differ from fiscal year data available in countries' budget documents Source: OECD, 27 March 2006. 
Chart 1: Net Official Development Assistance in 2005

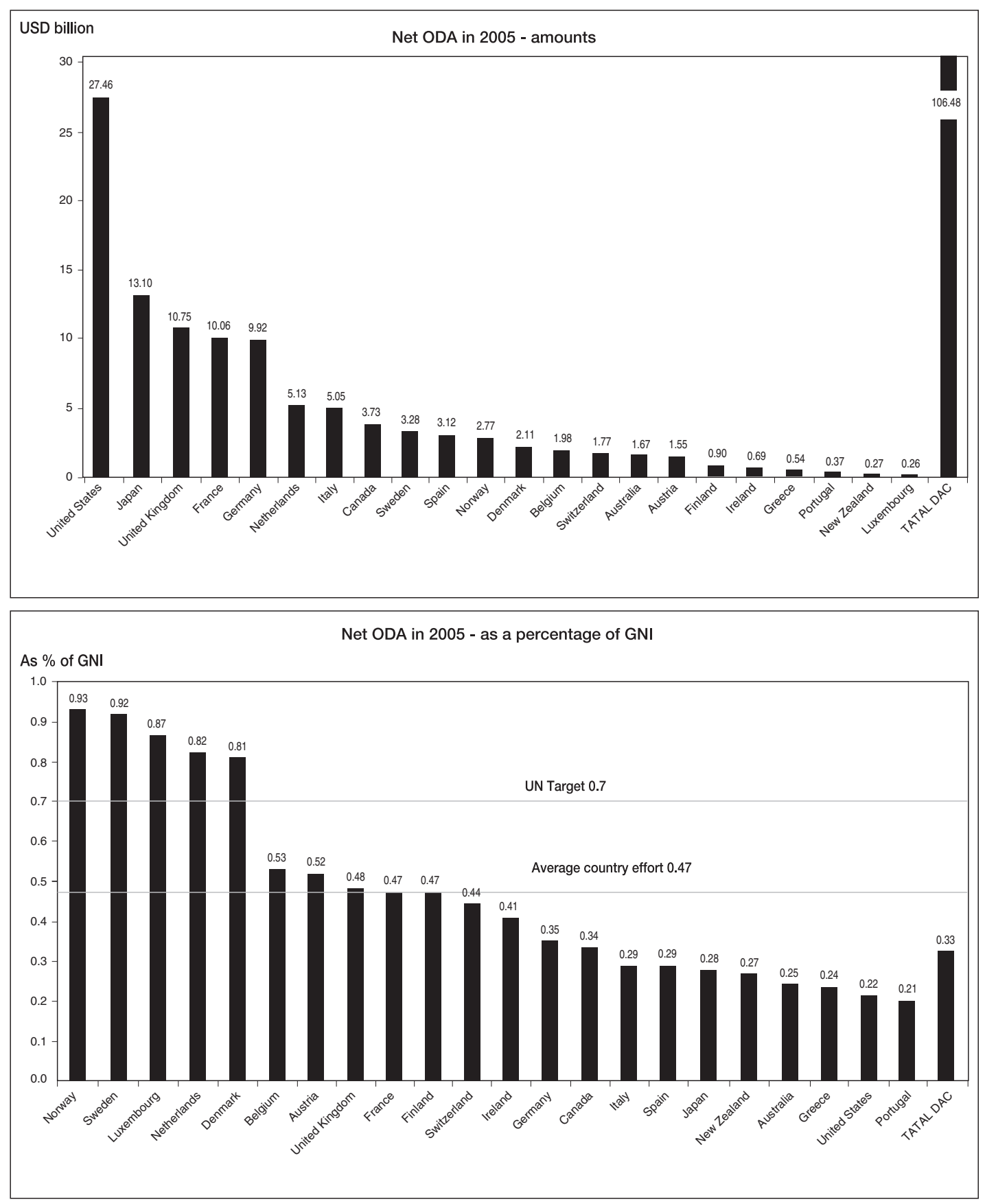

[자료: 주오이시디대표부] 